\title{
Artes marciais e esportes de combate na Educação Física Escolar: Interface
}

\section{Filosófica-Educacional na perspectiva discente}

\author{
Martial arts and combat sports in School Physical Education: Philosophical-Educational Inteface \\ in the student perpective
}

Artes marciales y deportes de combate en la Educación Física Escolar: Interfaz Filosófica-

Educativa en la perspectiva estudiantil

Eder Rodrigo Mariano

ORCID: https://orcid.org/0000-0002-3345-0003

Universidade Federal do Maranhão, Brasil

E-mail: eder.mariano@ufma.br

Deilson Serrão Pereira

ORCID: https://orcid.org/0000-0002-7538-1544

Universidade Federal do Maranhão, Brasil

E-mail: deilson2011@gmail.com

Deyvid Tenner de Souza Rizzo

ORCID: https://orcid.org/0000-0002-9622-9816

Universidade Federal de Mato Grosso do Sul, Brasil

E-mail: deyvidrizzo1@gmail.com

Sérgio Souza

ORCID: https://orcid.org/0000-0003-2633-9654

Universidade Federal do Maranhão, Brasil

E-mail: sergio.souza@ufma.br

Jefferson Campos Lopes

ORCID: https://orcid.org/0000-0003-3033-3845

Universidade Federal de Mato Grosso do Sul, Brasil

E-mail: jeffted@uol.com.br

Francisco Eduardo Lopes Da Silva

ORCID: https://orcid.org/0000-0001-8998-6803 Universidade Federal do Maranhão, Brasil

E-mail: f.eduardolopes@hotmail.com

Valber Ribeiro Costa Filho

ORCID: https://orcid.org/0000-0001-5722-912X Universidade Federal do Maranhão, Brasil

E-mail: valber.ribeiro.vr@gmail.com

\begin{abstract}
Resumo
Investigações qualitativas aplicadas às Artes Marciais e Esportes de Combate (AM\&EC) estão se propagando no meio acadêmico-científico. Este estudo teve como objetivo verificar a percepção dos estudantes quanto ao seu aprendizado mais relevante sobre Artes Marciais e Esportes de Combate, após serem submetidos a práticas pedagógicas nas aulas de Educação Física escolar. Participaram 150 alunos no $3^{\circ}$ ano do ensino médio, em Pinheiro (MA). Os participantes apresentaram o Termo de Consentimento Livre e Esclarecido (TCLE) assinado por um responsável e preencheram o questionário para ingressarem ao estudo. Após coletar os dados da pré e pós-intervenção, adotou-se a Análise de Conteúdo (Bardin, 2011) para análise categorial e, posteriormente, planificação e utilização do Software Statistical Package for the Social Sciences (SPSS), versão 24.0, IBM, 2016. O Teste Qui-quadrado buscou identificar diferenças significativas dos resultados obtidos e em todas as avaliações. Os resultados revelaram uma queda no percentual de alunos $(38 \%, \mathrm{n}=57)$, que apontavam como principal aprendizado "conhecer golpes" e "saber se defender". Novas asserções emergiram acusando como aprendizado mais significativo "conhecer novas culturas" $(33,4 \%, \mathrm{n}=51)$, "conhecer novas filosofias" $(28 \%, \mathrm{n}=46)$ e "diferenciar brigas de lutas" $(15,3 \%, \mathrm{n}=22)$. O estudo trouxe respostas positivas sobre a temática AM\&EC no âmbito escolar, contudo, há carência de novas pesquisas nesta vertente e em diferentes anos escolares e perspectivas. o resumo.
\end{abstract}

Palavras-chave: Educação física escolar; Artes marciais; Esportes de combate; Filosofia; Aprendizagem significativa.

\section{Abstract}

Incluir o resumo em inglês. Qualitative investigations applied to Martial Arts and Combat Sports (MA\&CS) are spreading in the academic-scientific environment. This study aimed to verify the students' perception regarding their 
most relevant learning about Martial Arts and Combat Sports, after being subjected to pedagogical practices in school Physical Education classes. 150 students in the 3rd year of high school participated, in Pinheiro (MA). Participants presented the Free and Informed Consent Form (FICF) signed by a responsible person and filled out the questionnaire to enter the study. Only the volunteers who attended (75\%) of the 12 proposed classes reached the end and completed the questionnaire again. The contents covered were related to the modalities of Judo, Jiu-Jitsu, Sumo, Greco-Roman and Huka-Huka (grappling fights); Boxing, Capoeira, Karate, Muay-Thai and Taekwondo (touch fights); and Sword, with Saber, Sword and Foil Sword (fights with implements), which were approached based on the attitudinal, conceptual and procedural dimensions, pointed out by Coll (2000). After collecting the pre- and post-intervention data, we adopted Content Analysis (Bardin, 2011) for categorical analysis and, subsequently, planning and use of the Software Statistical Package for the Social Sciences (SPSS), version 24.0, IBM, 2016. The Chi-square Test sought to identify significant differences in the results obtained and in all evaluations, the Confidence Interval $(\mathrm{CI}=95 \%)$ was considered, with significance level $(\mathrm{p}=0.05)$. The results revealed a drop in the percentage of students $(38 \%, \mathrm{n}=57)$, who pointed out as their main learning "to know blows" and "to know how to defend themselves". New assertions emerged as the most significant learning "knowing new cultures" $(33.4 \%, \mathrm{n}=51)$, "knowing new philosophies" $(28 \%, \mathrm{n}=46)$ and "differentiating brawls from fights" $(15.3 \%, \mathrm{n}=22)$. The study brought positive responses on the theme MA\&CS in the school context, however, there is a lack of new research in this aspect and in different school years and perspectives.

Keywords: School physical education; Martial arts; Combat sports; Philosophy; Meaningful learning.

\section{Resumen}

Las investigaciones cualitativas aplicadas a las Artes Marciales y los Deportes de Combate (AM\&DC) se están extendiendo en el ámbito académico-científico. Este estudio tuvo como objetivo verificar la percepción de los estudiantes sobre sus aprendizajes más relevantes sobre Artes Marciales y Deportes de Combate, luego de ser sometidos a prácticas pedagógicas en las clases de Educación Física escolares. 150 estudiantes del 3er año de secundaria participaron, en Pinheiro (MA). Los participantes presentaron el Formulario de Consentimiento Libre e Informado (FCLI) firmado por una persona responsable y completaron el cuestionario para ingresar al estudio. Solo los voluntarios que asistieron (75\%) de las 12 clases propuestas llegaron al final y completaron el cuestionario nuevamente. Los contenidos cubiertos estaban relacionados con las modalidades de Judo, Jiu-Jitsu, Sumo, GrecoRoman y Huka-Huka (luchas de agarre); Boxeo, Capoeira, Karate, Muay-Thai y Taekwondo (luchas de toque); y Espada, con Sable, Espada y Florete (luchas con implementos), que se abordaron desde las dimensiones actitudinal, conceptual y procedimental, señaladas por Coll (2000). Después de recoger los datos previos y posteriores a la intervención, adoptamos el Análisis de Contenido (Bardin, 2011) para el análisis categórico y, posteriormente, la planificación y el uso del Software Statistical Package for the Social Sciences (SPSS), versión 24.0, IBM, 2016. La Prueba de Chi-cuadrado buscó identificar diferencias significativas en los resultados obtenidos y en todas las evaluaciones se consideró el Intervalo de Confianza $(\mathrm{IC}=95 \%)$, con nivel de significación $(\mathrm{p}=0,05)$. Los resultados revelaron una caída en el porcentaje de estudiantes $(38 \%, \mathrm{n}=57)$, que señalaron como su principal aprendizaje "conocer golpes" y "saber defenderse". Surgieron nuevas afirmaciones como el aprendizaje más significativo "conocer nuevas culturas" (33,4\%, $\mathrm{n}=51)$, "conocer nuevas filosofías" $(28 \%, \mathrm{n}=46)$ y "diferenciar peleas de luchas" $(15,3 \%, \mathrm{n}=22)$. El estudio trajo respuestas positivas sobre el tema AM\&DC en el contexto escolar, sin embargo, hay una falta de nuevas investigaciones en esta área y en diferentes años escolares y perspectivas.

Palabras clave: Educación física escolar; Artes marciales; Desportes de combate; Filosofia; Aprendizaje significativa.

\section{Introdução}

A escola, na sua essência, detém a função de instituição socializadora, propulsora das relações humanas e promotora de atitudes. Os conteúdos atitudinais valem para justificar e explicar aquilo que executamos e relacionamos com os demais conhecimentos. Coll (2000, p. 14) considera a abordagem pela dimensão atitudinal indispensável para o desenvolvimento dos alunos, pois os remetem aos significados e sentidos da aprendizagem, que edificam a construção pessoal do estudante

No processo de aprendizagem de conceitos, o aluno correlaciona os conhecimentos já adquiridos a novos estímulos cognitivos e sensoriais vinculando-os a algo que os torne realmente significantes e os leve a compreensão dos fatos; ratificando a concepção de Coll (2000, p. 28) ao destacar que, ao serem absorvidos, os conteúdos permanecem vivos na memória e tornam-se propensos a se reproduzirem pelas ações do aprendiz.

Os Parâmetros Curriculares Nacionais (PCN), documento norteador da Educação brasileira, elaborado em 1997, já expressava que "ensinar e aprender atitudes requer um posicionamento claro e consciente sobre "o que" e "como" se ensina na escola (Brasil, 1997, p. 76), e reforçava a necessidade de haver a escolha pertinente do conteúdo aliada a ações pedagógicas 
eficazes para se efetivar a aprendizagem de atitudes, mesmo diante de um público com vasta miscelânea cultural.

O tema Ética, no ambiente escolar, é apresentado como uma proposta de trabalho que viabiliza a construção da autonomia moral do estudante, a partir de quatro eixos de conteúdo: Respeito Mútuo, Justiça, Diálogo e Solidariedade. Tais valores são referenciados no princípio da dignidade do ser humano, como rege nos fundamentos da Constituição Brasileira (Brasil, 1997, p.26).

A Ética é um Tema Transversal, proposto nos Parâmetros Curriculares Nacionais (PCN) (Brasil, 1997, p. 34) que deve ser contemplado nas aulas de Educação Física por ser um contributo indispensável na formação integral do discente.

Rosa (2020) faz alusão à Ética ao apontar a obra de Aristóteles, "Na Éthique à Nicomaque", na qual a Ética é uma virtude característica de uma pessoa altruísta que propaga o bem e se alegra ao agradar o próximo com pureza e franqueza; e reforça afirmando o papel da Ética que se revela em "uma ação emocional e racional, e confere, a quem a exprime, um estatuto estimável e exemplar".

No âmbito esportivo, a Ética está enraizada nos princípios, valores e propósitos do "fair-play" oriundos da Carta Olímpica, difundida pelo Comitê Olímpico Internacional (COI) e aliada a um código ético, elaborado em 1999, o qual reverencia a filosofia direcionada à integridade, à honestidade e à imparcialidade, expressos na moralidade por princípios que os indivíduos devem respeitar de maneira formal (Rosa, 2020, p. 36). Marivoet (2016), por sua vez, aponta o "fair-play" como meio de expressão de solidariedade, lealdade e amizade entre os desportistas, sendo elemento fundamental na composição da ética desportiva.

Ao ser abordada, por meio de práticas corporais e conceituais, nas aulas de Educação Física, o tema Ética favorece a construção de valores que levam à aprendizagem de normas condizentes ao exercício da cidadania e em prol de uma sociedade democrática. Neste caminho, a Base Nacional Comum Curricular (BNCC) preconiza a produção e partilha de atitudes, normas e valores, positivos e negativos, como parte inerente a todo processo de socialização, cuja intenção no ato de ensinar e aprender requer intervenção didática direcionada para este fim (Brasil, 2017, p. 217)

Apresentamos então, as Lutas, objeto de estudo desta investigação, como conteúdo proposto nas aulas de Educação Física escolar (EFE), desde a década de 90, através dos PCN (Brasil, 1997, p. 34), reconhecendo-a como ferramenta pedagógica extremamente valiosa e versátil no processo educativo, principalmente, quando se trata do tema Ética na escola, o qual está intimamente relacionado à tradição das lutas corporais que contemplam a dimensão atitudinal (Rufino \& Darido, 2012). No entanto, referir-nos-emos às lutas como Artes Marciais e Esportes de Combate (AM\&EC) devido sua abrangência ao se tratar da unidade temática.

Os PCN's relacionam os fatores inerentes às lutas e artes marciais pertinentes ao ensino da Educação Física que são importantes para o desenvolvimento das capacidades físicas; da utilização das habilidades motoras; respeito às regras e colegas; expressão de opiniões pessoais quanto a atitudes e estratégias, apreciação de esportes e lutas considerando alguns aspectos técnicos, táticos e estéticos.

Assim, as lutas são conceituadas pelo PCN's (1997) sendo:

Disputas em que o(s) oponente(s) deve(m) ser subjugado(s), mediante técnicas e estratégias de desequilíbrio, contusão, imobilização ou exclusão de um determinado espaço na combinação de ações de ataque e defesa. Caracterizam-se por uma regulamentação específica, a fim de punir atitudes de violência e de deslealdade (Brasil, 1997, p. 37).

Oliveira (2016) enfatiza a representatividade das AM\&EC para além das formas de combate e defesa; elas se sustentam sobre princípios filosóficos que as embasam e as conduzem. O respeito pelos pais, mestres e colegas; a conduta social e a disciplina; o compromisso, esforço e dedicação para atingir uma meta, são práticas oriundas de profunda filosofia de 
vida associada a crenças específicas.

No Brasil, o termo AM\&EC, conforme Del Vecchio e Franchini (2006) são utilizados nas práticas dentro das aulas de educação física escolar, trazendo consigo questões sociais eminentes sobre a sua importância no desenvolvimento motor, cognitivo e socio-afetivas.

Mesquita (2001) e Cartaxo (2011) enaltecem os valores éticos, morais e culturais das AM\&EC e reforça a necessidade de propagar tais conhecimentos nas aulas de EFE, tendo em vista sua relevância histórica e sociocultural e alerta para que, jamais, as AM\&EC fiquem engessadas no currículo escolar e na cientificidade da Educação Física; Nesta perspectiva, este estudo propõe a realização de intervenções pedagógicas com 13 modalidades de AM\&EC, com alunos do ensino médio.

Esta investigação tem como propósito verificar o efeito da práxis pedagógica na percepção desses estudantes quanto a sua aprendizagem e ao significado atribuído às AM\&EC no contexto educacional. Buscamos ainda, identificar o conhecimento dos alunos acerca das AM\&EC, enquanto conteúdo da EFE; apontar o grau de interesse dos alunos em conhecer o tema; e analisar a percepção e o entendimento dos alunos sobre as AM\&EC na perspectiva da dimensão atitudinal dos conteúdos.

\section{Metodologia}

Esta investigação trata-se de um estudo de caso, com abordagem qualitativa numa perspectiva construtivista, que segundo Yazan (2016) parte da realidade construída pelos envolvidos ao interagirem socialmente, no ambiente que os cerca, além de exprimir as inúmeras formas de interpretação da realidade (Yazan, 2016).

O estudo tem caráter descritivo, pois revela detalhes dos fenômenos ocorridos nos dados coletados, através de inquérito por questionário, ferramenta adotada na investigação, e apontada por Gil (2008), como uma técnica padronizada de coleta de dados.

\subsection{Aspectos Éticos da Investigação}

No que tange à ética em pesquisa, o estudo teve a aprovação do Comitê de Ética em Pesquisa da Universidade Federal do Maranhão-UFMA, viabilizando sua concretização. Esclarecemos a todos os alunos sobre os objetivos, os procedimentos, as condições de participação e desligamento do estudo, para então, iniciarmos as primeiras ações.

Para ingressarem na pesquisa, os voluntários tiveram que recolher a assinatura no Termo de Consentimento Livre e Esclarecido (TCLE) de seus responsáveis diretos, e tiveram que responder ao questionário, antes de iniciar as aulas. Para permanecerem e finalizarem o estudo, os estudantes tiveram que participar de, no mínimo, 8 encontros (75\% presença) e preencher o questionário, ao término das intervenções pedagógicas; caso contrário, seriam desligados da pesquisa.

\subsection{Amostra do Estudo}

Participaram da investigação somente estudantes matriculados que cursavam regularmente o $3^{\circ}$ ano do ensino médio, numa escola estadual de Pinheiro (MA). Dos 342 alunos que integravam as 10 turmas, buscamos atingir (45\%) deste quantitativo contemplando ( $\mathrm{n}=150$ a 160) participantes, conforme indica Bardin (2011). Assim, a amostra por conveniência foi composta por 168 alunos distribuídos nas turmas de número 301 a 305 .

Contudo, após o cumprimento dos critérios de exclusão, 150 estudantes concluíram o estudo, conforme ilustra o fluxograma amostral, a seguir: 
Figura 1 - Fluxograma Amostral.

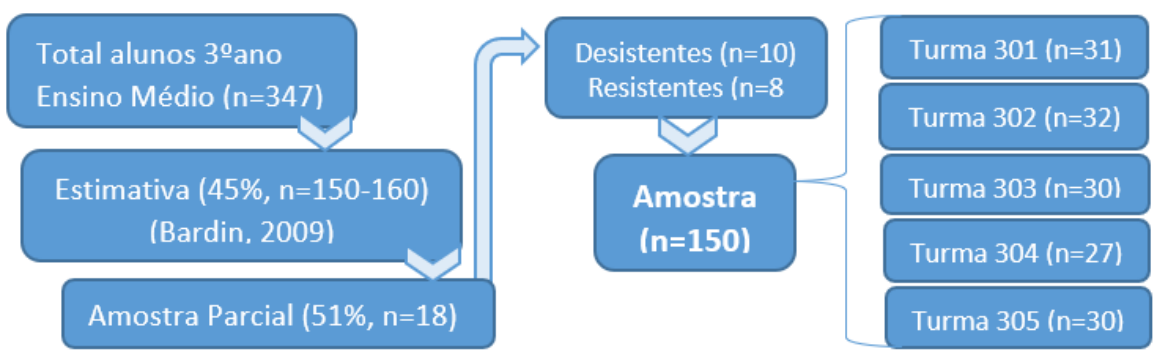

Fonte: Autores.

\subsection{As intervenções Pedagógicas}

Na referida instituição educacional foi instalado um tatame de $40 \mathrm{~m}^{2}$, numa sala de aula tradicional, onde ocorreram as aulas teóricas e práticas. As aulas foram elaboradas no formato Power Point e nele continha informações expressas por meio de textos, fotos e vídeos sobre a unidade temática. Foi elaborado um plano de aula para cada modalidade de AM\&EC, de modo a contemplar aquelas que envolvem as técnicas de agarre, as ações de toque no oponente, e o uso de implementos. Assim, de forma aleatória, foram elencadas seis modalidades para cada turma, conforme mostra Quadro 1.

Quadro 1. Relação das Modalidades de Artes Marciais e Esportes de Combate para cada turma.

\begin{tabular}{|c|c|c|c|c|}
\hline \multicolumn{7}{|c|}{ Modalidades de Artes Marciais e Esportes de Combate } \\
\hline Turma 301 & Turma 302 & Turma 303 & Turma 304 & Turma 305 \\
\hline Jiu-jitsu e Huka- & Judô e Huka- & Greco-Romana e & Sumô e Greco- & Sumô e Judô, \\
Huka; Capoeira e & Huka; Karatê e & Jiu-Jitsu; Boxe e & Romana; Karatê & Muay-Thai e \\
Muay-Thai; & Boxe; Espada e & Capoeira; Espada e & e Taekwondo; & Taekwondo, \\
Florete e Sabre. & Florete. & Sabre. & Florete e Sabre. & Sabre e Florete. \\
& & & & \\
\hline
\end{tabular}

Fonte: Autores.

O método adotado para abordagem das AM\&EC foi sustentado nas dimensões dos conteúdos, definidos por Coll (2000), como meio de aprendizagem de conceitos, reconhecimento de significados e ações características das modalidades. O roteiro das aulas consistiu, na esfera conceitual, a explanação do contexto histórico-cultural, os precursores, o propósito de criação das Artes Marciais, sua ascensão e sua posição mundial, na atualidade. No campo da prática, foram propostas atividades visando o conhecimento e aprendizagem de técnicas executadas num ambiente fechado (Malta et al., 2019) para melhorar o movimento, por meio do feedback extrínseco; bem como o desenvolvimento da inteligência tática (Greco, 2006) por meio dos jogos de combate. Na perspectiva atitudinal, levantamos algumas questões no momento do combate, por exemplo, "ele é seu inimigo ou oponente? ", "você tem que vencer a qualquer custo?", "lutar significa brigar?”; enquanto, nas aulas teóricas, ressaltamos os valores éticos e morais, e princípios filosóficos contidos nas origens das AM\&EC. Foram ministradas, no período de 6 semanas, 2 aulas semanais (teoria e prática), com duração total de 140 minutos.

\section{Análise de Dados}

Adotamos a Análise de Conteúdo (AC) como ferramenta de exploração os resultados do obtidos no inquérito, visto que é um recurso que favorece uma descrição objetiva, sistemática e quantitativa das informações contidas nas comunicações, e tem como propósito interpretar as informações e codificá-las, para então, submetê-las ao programa de análise estatística (Bardin, 2009, p.51). 
Para Bardin (2011), o termo análise de conteúdo designa:

Um conjunto de técnicas de análise das comunicações visando a obter, por procedimentos sistemáticos e objetivos de descrição do conteúdo das mensagens, indicadores (quantitativos ou não) que permitam a inferência de conhecimentos relativos às condições de produção/recepção (variáveis inferidas) destas mensagens (Bardin, 2011, p. 47)

Assim, inicia-se com uma preleção dos métodos quantitativos e qualitativos, apresenta a pesquisa qualitativa na observação de autores clássicos na área e introduz o método de análise de conteúdo com fundamento em (Bardin,2011).

Neste sentido, foi realizada uma análise categorial, respeitando o procedimento técnico proposto por Bardin (2011), com a sistematização das ideias após a leitura das justificativas nas questões abertas contidas no inquérito e o recorte em unidades de registro de todo conteúdo das respostas dissertativas dos estudantes. Identificamos as palavras-chaves e agrupamos conforme a correlação entre elas, buscando compreender o sentido das respostas e seu real significado. Por último, realizou-se a comparação e correlação dos dados conforme a similaridade das respostas que foram revistas, comparadas e, previamente agrupadas em categorias significativas, considerando a frequência, a direção e a intensidade das informações, na hipótese de que quanto mais citada, maior sua importância (Bardin, 2011, p.121).

Após concretizada a Análise de Conteúdo, foi atribuído um código referente a cada resposta, considerando as respectivas categorias, em ambos momentos, pré e pós intervenção pedagógica. Os códigos foram inseridos no Programa Software Excel 2000 para planificação dos dados. Em seguida, utilizamos o Software Statistical Package for the Social Sciences (SPSS), versão 24.0, IBM, 2016, o qual possibilitou realizar a análise estatística por meio de correlação, regressão, comparação dos dados codificados.

$\mathrm{Na}$ sequência, foi feita a análise estatística por meio do Teste Qui-quadrado visando identificar diferenças significativas dos resultados obtidos nos distintos momentos, pré e pós-intervenção pedagógica, adotando-se os mesmos parâmetros. Em todas as avaliações, foi considerado o Intervalo de Confiança (IC=95\%), com nível de significância $(p=0,05)$ para a validação das hipóteses investigadas.

\section{Resultados e Discussão}

Os resultados alcançados mostram o quão é relevante a atitude docente em proporcionar o conhecimento de uma unidade temática tão enriquecedora aos discentes. $\mathrm{Na}$ EFE, o professor pode e deve oportunizar experiências que instiguem os princípios básicos para uma convivência sadia e democrática no ambiente escolar e na sociedade. A medida que o aluno, no decorrer das aulas, vivencia e reconhece valores pessoais, como diálogo, justiça, respeito e a solidariedade, sua formação éticacidadã se solidifica (Impolcetto \& Darido, 2007).

Desta forma é possível dizer que prática docente é a ação intencional do professor que vislumbra o ensino e a aprendizagem do aluno. Sendo o professor ser histórico e cultural, sua ação é permeada por um conjunto de saberes que o constitui: saberes pessoais, saberes provenientes da formação para o magistério, saberes provenientes dos materiais didáticopedagógicos que utiliza e saberes provenientes da própria atividade docente (De Araújo Silva et al., 2021).

O envolvimento dos alunos com o tema AM\&EC no ambiente escolar não deve visar a formação de lutadores $\mathrm{e}$ atletas, mas, priorizar a construção de cidadãos críticos, solidários e participativos. Acredita-se que exercício do cuidado, da cumplicidade e da cooperação entre os participantes durante as aulas podem promover e consolidar um vínculo de confiança entre os alunos. Neste entendimento, Rufino e Darido (2013) destacam a riqueza e a diversidade cultural e filosófica das AM\&EC como pontos temáticos merecedores de um tratamento pedagógico refinado neste cenário educativo.

Com intuito de averiguar o conhecimento discente sobre a presença das AM\&EC no currículo da EFE, indagamos aos participantes e obtivemos as seguintes respostas expressas no Gráfico 1. 
Gráfico 1 - Conhecimento dos estudantes sobre as AM\&EC enquanto conteúdo da Educação Física.

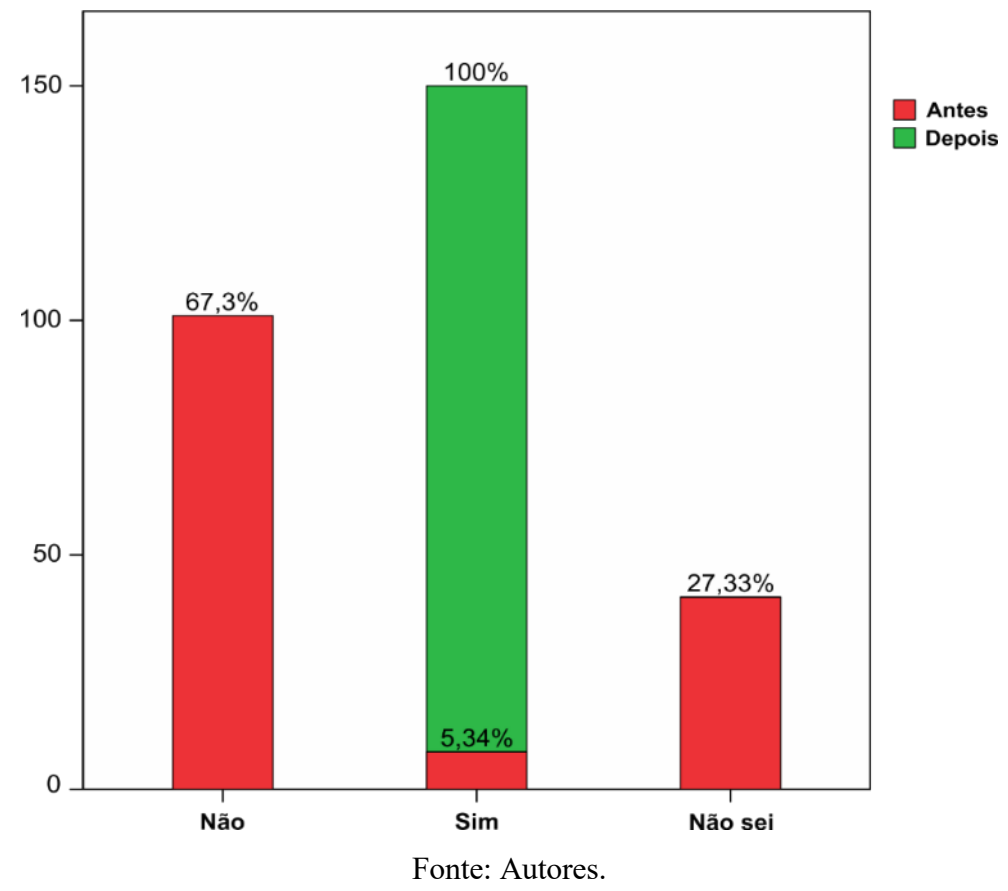

Verificamos que as AM\&EC são conhecidas no ambiente escolar por apenas 8 alunos (5,43\%), enquanto 41 deles $(27,33 \%)$ alunos não souberam responder. $\mathrm{O}$ resultado mais expressivo revela uma triste realidade, 101 (67,3\%) alunos não tinham o conhecimento de que as AM\&EC compunham o rol de unidades temáticas da Educação Física.

Mesmo sendo um elemento da cultura corporal de movimento na EFE, as AM\&EC são subvalorizadas e sua ausência nas escolas é justificada, pelos professores, devido à falta de espaço e de materiais adequados, à ausência do tema no processo de formação profissional e, sobretudo, à associação das AM\&EC a questões da violência e agressividade. Costa (2017) salienta que a aversão de professores de Educação Física na abordagem das Artes Marciais na escola está vinculada a uma repercussão negativa na visão dos familiares por acreditarem que instiga a violência e a agressividade (Mariano et al., 2021).

O desconhecimento desta unidade temática da Educação Física revela a limitação discente quanto às possibilidades de aprendizagem de conteúdos diversificados. No contexto da EFE, o preconceito em relação às AM\&EC é evidente e a resistência em compreender o assunto levam os estudantes a uma lacuna intelectual. Nesta ótica, Rodrigues e Antunes (2019) apresentam as AM\&EC como detentora de um conjunto de conteúdos e indispensáveis no desenvolvimento integral do aluno, e ressalta que diferentes modalidades favorecem a ampliação do acervo motor, aprimoram o desempenho mental, e inspiram condutas positivas por trabalhar o respeito ao próximo, a autoavaliação e o auto aperfeiçoamento.

Observou-se, no entanto, que todos estudantes passaram a conhecer diversas modalidades de AM\&EC nos contextos conceitual, prático e social, ampliando seus horizontes.

A motivação para participar nas aulas de Educação Física é um tema debatido há décadas no cenário educacional (Betti, 1995). Procuramos detectar o nível de interesse dos alunos em participar das aulas de AM\&EC na Educação Física, e por ser um conteúdo inédito, causa receio e incertezas de diferentes naturezas. O Gráfico 2 nos indica o quão interessados os alunos se mostraram em conhecer; a temática na EFE. 
Gráfico 2 - Nível de interesse dos estudantes em participar das aulas de AM\&EC na Educação Física.

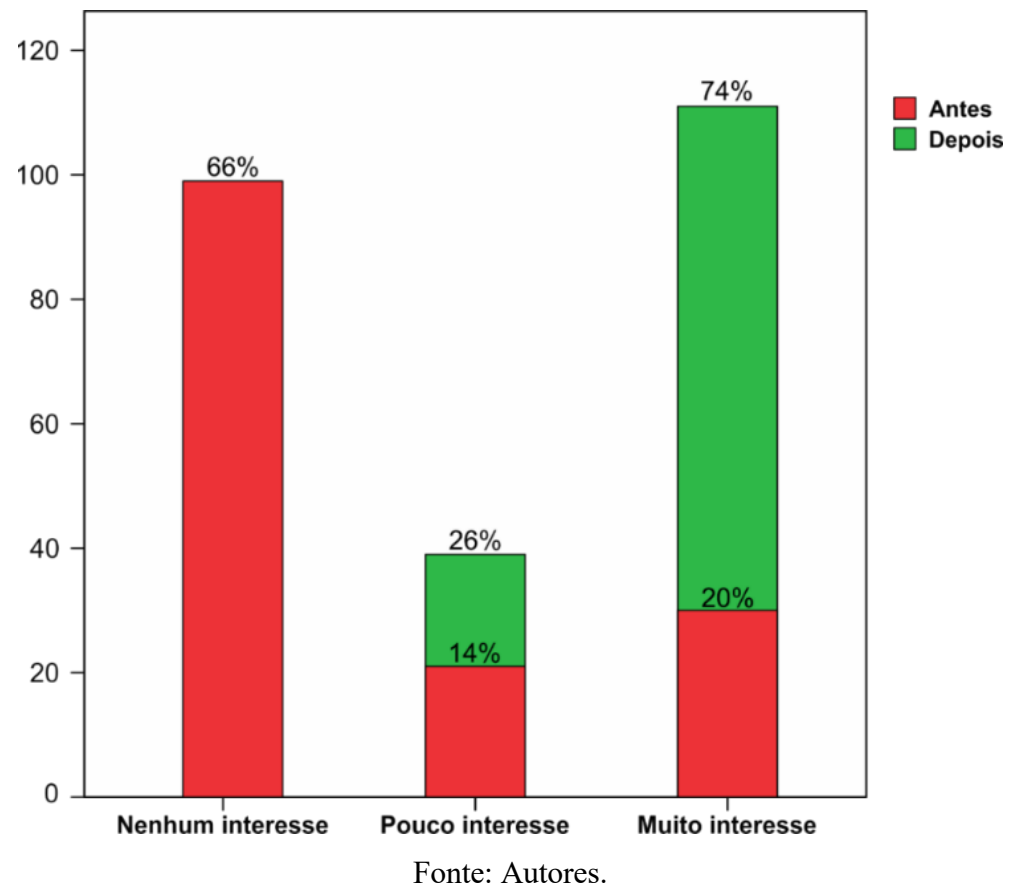

O interesse dos alunos em conhecer a unidade temática foi apontado no Gráfico 2, e apresentou um resultado preocupante, pois o percentual de alunos totalmente desinteressados pela temática é bastante expressivo (66\%, n=99). Dos 150 alunos envolvidos no estudo, apenas 21 (14\%) apresentaram pouco interesse em conhecer as AM\&EC, enquanto 30 participantes (20\%) estavam bastante interessados pelo tema.

A literatura científica nos mostra inúmeros estudos que buscaram identificar, nos alunos e professores, as causas de desmotivação e da ausência nas aulas de EFE.

A pesquisa de Betti (1995) investigou a postura do professor EFE no exercício de sua profissão, através da opinião dos alunos, e, como resposta, constatou que alguns professores "pegam" a bola e entregam para os alunos "jogarem". Tal conduta causa aversão e resistência dos alunos às aulas, visto que eles expressaram interesse em aprender algumas técnicas de modalidades esportivas e queriam ser orientados quanto à execução dos fundamentos. Estabelece-se então, um ciclo vicioso e constrangedor, pois, sem orientação, a prática não tem sentido, e sem a prática não há evolução cognitivo-motora que o estimule a realizar novas experiências motoras.

A prática analítica-sintética envolve a execução dos fundamentos por partes, método este que, segundo Leonardi et al., (2017), possibilita a orientação e correção dos gestos técnicos favorecendo a aprendizagem. Tal método estimula a participação do aluno pois não há o confronto direto.

$\mathrm{Na}$ investigação realizada com professores de Educação Física, Darido (2012) nos revelou que, dos 30 participantes, 25 correlacionaram a falta de habilidade e o autojulgamento de incapacidade como sendo as causas de desinteresse e absenteísmo dos alunos pelas aulas de EFE. Ressaltamos que, em todas as intervenções pedagógicas foram desenvolvidas atividades com o predomínio das habilidades motoras fechadas, cujo foco centrava-se na aprendizagem das técnicas específicas da modalidade, como a ginga (Capoeira), socos (Boxe), desequilíbrios (Sumô), chutes (Taekwondo), estocadas (Esgrima), projeções (Judô), entre outros.

Pizani (2016) cita a falta de propósito na elaboração das aulas, a valorização da monocultura esportiva e a ausência de orientação do professor como fatores desestimulantes que resultam no baixo índice de participação discente na EFE. Andrade e 
Tassa (2015), por sua vez, ressalta a proliferação dos games e dos jogos eletrônicos como elemento crucial de desmotivação e de afastamento discente das aulas práticas de EFE.

Identificou-se, nos dias atuais, o que Luz (2014) apontava há quase uma década, a postura de abdicação dos docentes na abordagem das AM\&EC na EFE. O autor entende que tal atitude reflete um desleixo, pois, os professores têm consciência dos contributos deste conteúdo na formação pessoal dos estudantes, mas devido a demanda de estudos e pesquisas na preparação das aulas, eles optam por outro conteúdo, ainda mais quando se trata dos elementos filosóficos das AM\&EC.

Amparada pelos Parâmetros Curriculares Nacionais do Ensino Médio (Brasil, 1997), Darido (2004), valoriza o trato pedagógico voltado para a aprendizagem significativa do aluno, pois estabelece uma relação de reciprocidade entre ele e o conteúdo. A autora defende a contextualização de experiências cotidianas aliadas aos conhecimentos adquiridos, como meio de abordagem do conteúdo, pois o aluno deixa a condição de espectador e torna-se proativo no processo educacional, participando, inclusive, na seleção dos conteúdos, aguçando ainda mais, seu interesse pelas aulas na EFE.

A aprendizagem significativa, segundo Sacristán (2013, p. 54), é essencial no processo educativo por colaborar na conscientização dos alunos acerca de seu papel social, mediante uma postura responsável e solidária, adquirida a partir da reflexão de suas ações e reações diante das situações que o permeiam. $\mathrm{O}$ autor reforça que a aprendizagem se torna significativa no instante em que o aprendizado faz sentido à sua realidade e ao seu cotidiano.

Nesta perspectiva, apontamos, no Gráfico 3, quais foram as aprendizagens significativas reveladas pelos estudantes do ensino médio ao participarem das intervenções pedagógicas de AM\&EC na escola.

Gráfico 3 - Aprendizagens significativas acerca das AM\&EC na Educação Física segundo a percepção dos discentes.

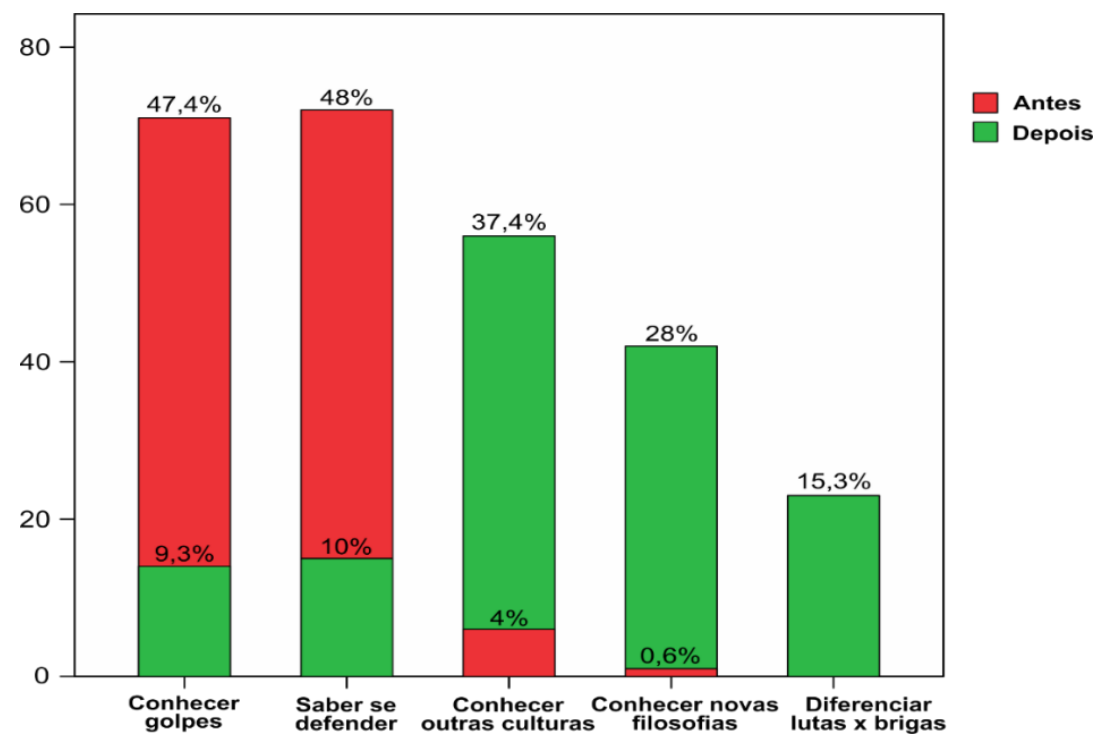

Fonte: Autores.

No pré-intervenção, os alunos indicaram como aprendizagem mais significativa com as aulas de AM\&EC o "conhecimento de golpes" $(47,4 \%, \mathrm{n}=71)$ e o "saber se defender" $(48 \%, \mathrm{n}=72)$ com percentuais bastante expressivos; enquanto apenas $6(4 \%)$ alunos apontaram a aprendizagem de "novas culturas", e somente $1(0,6 \%)$ aluno entendeu que o mais importante a se aprender com AM\&EC seria "conhecer novas filosofias".

Detectou-se então, o desprestígio dos estudantes em relação aos conhecimentos filosóficos e culturais do referido conteúdo e citamos Landim et al (2017) para justificarmos tal postura ideológica discente, visto que, a cultura e a filosofia das AM\&EC nos remete a princípios éticos que implicam, antes de tudo, na atitude de proteção e respeito ao seu semelhante. 
A relação teórico-prática estabelecida, pelo professor de EFE, na aplicação dos conteúdos contribui na assimilação de saberes filosófico-culturais determinantes no desenvolvimento e socialização dos estudantes (Coll, 2000, p. 13). A aprendizagem significativa parte da premissa de que o aprendizado é o resultado da interpretação de uma nova informação, a partir do que já sabíamos. Coll (2000) reforça afirmando que "não basta somente reproduzir informação nova, também é preciso assimilá-la ou integrá-la aos nossos conhecimentos anteriores" (p. 32) e acrescenta: "uma pessoa adquire um conceito quando é capaz de dotar de significado uma informação que lhe é apresentada, ou seja, quando compreende esse material, em suas próprias palavras" (p. 25).

Por trabalhar aspectos relativos à cultura e aos valores morais e éticos de desenvolvimento das responsabilidades, Lopes (2021) ressalta a necessidade de um olhar pedagógico refinado ao trabalhar as AM\&EC visando o desenvolvimento integral humano na contemporaneidade.

De acordo com os PCNs (Brasil, 1997, p. 49) apesar das palavras moral e ética possuírem o mesmo significado etimológico (mores, no latim e ethos, no grego, remetem a definição de costume) os conceitos incorporaram ao longo do tempo significações diferenciadas. A moral é considerada como "o conjunto de princípios, crenças e regras que orientam o comportamento dos indivíduos nas diversas sociedades", enquanto a ética é classificada como a "reflexão crítica da moral".

Tematizar a ética, na EFE, contribui para a formação do cidadão íntegro. Utilizar as AM\&EC como recurso pedagógico direcionando-a para o desenvolvimento de valores pessoais enaltece suas raízes e princípios benevolentes no ato de educar (Cazetto, 2009, p, 155). O autor ainda atesta que ensinar AM\&EC ultrapassa a esfera biomecânica, e nos remete à aprendizagem e à compreensão da cultura, dos ensinamentos e do espírito das AM\&EC (Cazetto, 2009, p. 156).

Mesquita (2001), confirma a importância de se trabalhar os aspectos filosóficos das AM\&EC na EFE, mas destaca a relevância ao desenvolvermos as AM\&EC com olhar voltado para o seu papel no campo político-social de seu país de origem, ressaltando, dessa maneira, a expressiva influência das AM\&EC enquanto manifestação cultural.

Rufino E Darido (2012, p. 293) atestam que "o respeito ao outro e às regras, a solidariedade, a tolerância e o repúdio à violência precisam estar presentes na prática do professor, pois uma prática corporal não ensina valores se não houver intencionalidade". Assim, a abordagem de conteúdos no âmbito da dimensão atitudinal no contexto da EFE deve ser bem clara e esclarecedora.

Em cada intervenção pedagógica ocorreu a explanação das origens e os significados das AM\&EC, buscando esclarecer os sentidos contidos nos rituais de diferentes culturas e filosofias. Os indígenas do Xingu, praticam o Huka-Huka, Arte Marcial raiz, como parte da celebração do luto de um integrante da tribo; , com os indígenas do Xingu, com os indígenas, a passagem para a fase adulta, formação de caráter, a demonstração de valentia, coragem e superação, e discutia-se acerca dos valores e

As primeiras reflexões sobre a ética no campo desportivo, emergiram no século XIX, com base no Espírito Olímpico, idealizado por Pierre de Coubertin, cujo foco principal era tornar os Jogos Olímpicos uma escola de valores. Nesta perspectiva, Rosa (2020) aponta o Judô como um conteúdo que une as dimensões intelectuais, esportivas e espirituais, |cuja inspiração de seu criador, Jigoro Kano, foi pensar em um caminho para educar o praticante e lhe assegurar seu aperfeiçoamento físico e moral. O autor esclarece que no "Judô Tradicional", imperava a "ética marcial renovada ou educativa" onde o oponente é apenas um adversário; ao passo que, no "Judô Desportivo", a ética é pautada no cumprimento dos regulamentos da competição e o desafiante é considerado um adversário.

Etimologicamente, ética e moral exprimem o conjunto de costumes e valores que regulamentam, guiam e prescrevem nossas condutas, e são ponderadas nos valores de justiça e igualdade, tanto no campo social quanto no desportivo. A boa conduta é o espelho da virtude, e o fair-play, comportamento de autocontrole que prima pelo respeito e integridade, defende a sobreposição da razão pela emoção (Rosa, 2020). 
Identificamos, no gráfico 3, que a aprendizagem significativa dos alunos estava atrelada ao conhecimento de novas culturas, porém, dos 150 envolvidos, apenas 6 acreditavam que as AM\&EC iriam promover tal aquisição; no entanto, após a participação nas aulas teóricas e práticas, registramos um aumento extremamente valioso de (30\%), o que representa um quantitativo superior de 50 alunos que passaram a valorizar o conteúdo e reconhecê-lo como elemento que promove a aprendizagem intelectual.

Na esfera dos princípios e virtudes éticas, a obra de Carvalho (2015), "O Caminho do Guerreiro", nos traz a seguinte reflexão sobre as artes de combate:

O caminho trilhado pelos praticantes de Artes Marciais é sustentado por dois pilares: a virtude da moral e a virtude intelectual. A virtude da moral seria provinda da prática social, do hábito e das vivências do dia a dia; já a virtude intelectual, advém da faculdade de compreender a partir do ensino, da experiência e do tempo (Carvalho, 2015, p. 11)

A Ética é uma disciplina da Filosofia a qual possui a moral como objeto de estudo. Para Carvalho (2015, p 39) “[...] a ética é uma teoria ou ciência que se preocupa com o comportamento moral dos homens e mulheres em sociedade [...]".

Rohling (2017) em sua obra $A$ educação Moral, cita que a moral representa um número pequeno de princípios que regem a humanidade e que se violados são passíveis de repreensão. Essa repressão perpassa pela humanidade, que é a atual sociedade, na qual se convive, também considerada como a entidade defensora da moral. É, a sociedade, a grande responsável pela conservação e acréscimo da moral de cada geração.

No âmbito educacional, o significado de moral, baseado na obra de Rohling (2017), nos alerta que, o ensinamento só é adequado se estiver dentro do que é aceito pela sociedade, se assim estiver, que dizer que este indivíduo recebeu uma educação apropriada. Contudo, este ensinamento se dá por meio de regras e valores que são estabelecidos e agregados por meios morais. É esta mesma educação que faz com que um indivíduo se sinta membro ou parte integrante de uma sociedade. A educação deve estar sintonizada desde o meio moral até o processo de desenvolvimento pelo qual esteja passando o indivíduo.

A prática das AM\&EC pode refletir positivamente no comportamento do praticante, em quaisquer momentos e situações da vida cotidiana, levando-nos a agir coragem, retidão e honra. Agir com honestidade e o respeito ao próximo, reluz o autocontrole, a superação de si mesmo contra os vazios e as más intenções. A educação por meio de tais virtudes realça os valores de convívio em sociedade, que, na atualidade está fortemente contaminada pelo consumismo e individualismo. Neste contexto, Carvalho (2015) ressalta a relevância do ensino das AM\&EC como forma de resistência às incoerências entre o pensar e o agir no exercício da cidadania.

Gomes (2013) relata que as AM\&EC podem ser utilizadas como prática de esporte sugerindo atividades com o aluno que vão além do movimento corporal, buscando passar a não violência e autodefesa, como uma de suas filosofias, servindo assim como um dos instrumentos no auxílio da pratica didático pedagógica da EFE.

Hammami, (2018, p.74) A popularidade desses esportes está florescendo em diferentes idades, por uma variedade de razões, tais como manter habilidades físicas, melhorar o equilíbrio, flexibilidade e força, e obter benefícios para a saúde. As artes marciais também podem ser consideradas como uma excelente ferramenta terapêutica que desenvolve concentração, socialização, autoestima, aprimora a disciplina e autodefesa na população mais jovem.

\section{Conclusão}

Esse artigo não trata de estabelecer classificações nem tentar determinar qual a maneira mais correta de tratar este tema. O objetivo central foi o de lançar um olhar e analisar a produção de conhecimento que atravessa a temática das AM\&EC, decalcando-a em uma rede de significados, sem desconsiderar suas disputas e tensões, mas, atentando para os efeitos que elas produzem na constituição dessas práticas corporais na contemporaneidade. 
Na pesquisa realizada, o ensino das AM\&EC no ambiente escolar tem sido abordado muitas vezes de forma aquém do que se espera, e há defasagem de estudos proponentes a esta temática, bem como, a utilização de abordagens pedagógicas que complementem a introdução das lutas no ambiente escolar. Um melhor aprimoramento de professores para uma melhor prática pedagógica deve existir para que haja uma melhor compreensão dos alunados frente a essa proposta. Vale ressaltar que quando bem direcionado, se torna um elemento essencial na demanda sociocultural, bem como, agregando o alavanque de outras mais competências que construam nos alunos variadas formas de compreensão.

Em conclusão, é preciso entender que as AM\&EC, nos trazem a possibilidade de ensinar para a vida, compreendendo a importância de estar no mundo de forma legitima, humana, onde possamos entender nosso papel na sociedade.

Por fim, considera-se a necessidade e importância de futuros estudos investigarem as artes marciais e esportes de combate na educação física escolar com interface na perspectiva discente, especialmente no tocante a aprendizagem em nível escolar, pois, dessa forma, o comprometimento de um professor com a educação de todos os alunos pode representar um diferencial na formação humana plena das pessoas, favorecendo, por exemplo, a aprendizagem de valores positivos por meio do esporte como forma de organizar uma sociedade mais ética em geral.

\section{Referências}

Andrade, T. E., \& El Tassa, K. O. M. (2015). Motivação nas aulas de Educação Física no ensino médio. Lecturas: Educación física y deportes, (203), 11.

Bardin, L. (2011). Analise de Conteúdo. Ed. Revista Ampliada.

Betti, I. C. R. (1995). Educação física escolar: a percepção discente. Revista Brasileira de Ciências do Esporte, 16(3), $158-67$.

Brasil, S. (2017). Base Nacional Curricular Comum-BNCC.

Brasil. (1997) Introdução aos Parâmetros Curriculares Nacionais.Ministério da Educação. Secretaria de Educação Fundamental.

Cartaxo, C. A. (2011). Jogos de Combate: atividades recreativas e psicomotoras: teoria e prática. Vozes.

Carvalho, L. C. V. (2015). Fatores para a motivação ou desmotivação à participação nas aulas de Educação Física. RBFF-Revista Brasileira de Futsal e Futebol, 7(27), 548-553.

Cazetto, F. F. (2009). A influência do Esporte Espetáculo sobre o modelo de competição dos mais jovens no judô.

Coll, C., Pozo, J. I., Sarabia, B., \& Valls, E. (2000). Os conteúdos na reforma: ensino e aprendizagem de conceitos, procedimentos e atitudes. In Os conteúdos na reforma: ensino e aprendizagem de conceitos, procedimentos e atitudes (pp. 182-182).

Costa, R. M. (2017). Lutas e artes marciais nas aulas de educação física: uma revisão da literatura. Revista Gestão Universitária. http://www.gestaouniversitaria.com.br/artigos/lutas-e-artes-marciais-nas-aulas-de-educacao-fisica-uma-revisao-da-literatura .

Darido, S. C. (2004). A educação física na escola e o processo de formação dos não praticantes de atividade física. Revista brasileira de educação física e esporte, 18(1), 61-80.

Darido, S. C. (2012). Educação física e temas transversais na escola.de Melo, F., \& Barreira, C. R. A. (2015). As fronteiras psicológicas entre violência, luta e brincadeira: as transições fenomenológicas na prática da capoeira. Movimento, 21(1), 125-138.

De Araújo Silva, S. C., Rabelo, A. K. P. W., Souza, C. D. M. O., Habibe, C. D. R., Habibe, F. H., \& Santos, M. J. A. (2021). Formação de educadores: desafios e possibilidades para a práxis pedagógica na educação infantil. Brazilian Journal of Development, 7(3), 21537-21554.

Del Vecchio, f. B., \& Franchini, e. (2006). Lutas, artes marciais e esportes de combate: possibilidades, experiências e abordagens no currículo da educação física. Formação profissional em educação física: estudos e pesquisas. Biblioética, 1, 99-108.

Gil, A. C. (2008). Métodos e técnicas de pesquisa social. Atlas, 199.

Gomes, N. C., de Barros, A. M., de Freitas, F. P. R., Darido, S. C., \& Rufino, L. G. B. (2013). O conteúdo das lutas nas séries iniciais do ensino fundamental: possibilidades para a prática pedagógica da Educação Física escolar. Motrivivência, (41), 305-320.

Greco, P. J. (2006). Conhecimento tático-técnico: eixo pendular da ação tática (criativa) nos jogos esportivos coletivos. Revista brasileira de educação física e esporte, 20(5), 210-212.

Hammami, N., Hattabi, S., Salhi, A., Rezgui, T., Oueslati, M., \& Bouassida, A. (2018). Combat sport injuries profile: a review. Science \& Sports, 33(2), 7379.

Impolcetto, F. M., \& Darido, S. C. (2007). Ética como tema transversal: possibilidades de aplicação nas aulas de Educação Física Escolar. Motriz. Journal of Physical Education. UNESP, 14-23. 
Research, Society and Development, v. 10, n. 7, e1810715775, 2021

(CC BY 4.0) | ISSN 2525-3409 | DOI: http://dx.doi.org/10.33448/rsd-v10i7.15775

Landim, R. A. A., de Nader, P. P. D. S., de Azevedo, I. O. S., Rei, B. D., \& Pelegrino, C. M. P. Q. (2017). O Conteúdo Lutas E O Tema Transversal Ética Nas Aulas De Educação Física: Reflexões E Experiências. Temas em Educação Física Escolar, 2(1), 123-136.

Leonardi, T. J., Galatti, L. R., Scaglia, A. J., De Marco, A., \& Paes, R. R. (2017). Pedagogia do esporte: sinalização para a avaliação formativa da aprendizagem. Pensar a Prática, 20(1).

Lopes, J. C. (2021). Lutas na Educação Física Escolar: caminhos e possibilidades no ensino e aprendizagem. Editora Dialética.

Luz, S. (2014). Artes marciais na escola: um olhar diferente para a educação física escolar na perspectiva do currículo cultural. São Paulo: Universidade de São Paulo. <http://www.gpef.fe.usp.br/semef\%202014/Relato\%20Suel\%20artes\%20marciais.pdf>.

Malta, L. H. R., Pagliarini, A. T. R., Florentino, J. A. A., \& Toigo, A. M. (2019). O efeito da frequência de feedback extrínseco do tipo conhecimento de resultado na aprendizagem do fundamento de finalização no futsal. Revista Interdisciplinar de Promoção da Saúde, 2(1), 40-47.

Mariano, E. R., da Silva, F. E. L., Souza, S., Rizzo, D., Rosa, V. A. V., \& Monteiro, L. F. (2021). Elas podem se machucar: As Lutas no combate ao preconceito de gênero na Educação Física Escolar. Research, Society and Development, 10(3).

Marivoet, S. (2016). Ética do Desporto-Princípios, Práticas e Conflitos. Análise sociológica do caso português durante o Estado Democrático do século XX.

Mesquita, C. (2001). Artes Marciais: uma prática de educação ou violência. Judô-Evolução Técnica e Competição. João Pessoa, Brasil: Editora Idéia.

Oliveira, L. R. (2016). Artes marciais e educação física escolar: por articulações concretas no ensino (Masters dissertation, Universidade de São Paulo).

Pizani, J., Barbosa-Rinaldi, I. P., de Miranda, A. C. M., \& Vieira, L. F. (2016). (Des) motivação na educação física escolar: uma análise a partir da teoria da autodeterminação. Revista brasileira de ciências do esporte, 38(3), 259-266.

Rodrigues, A. I. C., \& Antunes, M. M. (2019). Ensinando lutas na escola: percepções e expectativas de dirigentes do ensino fundamental. Revista Valore, 4(1), 885-899.

Rohling, M. (2017). Durkheim, Rawls Y La Educación Moral. Revista Brasileira de Educação, 22(71).

Rosa, V. (2020). O desporto em análise.

Rufino, L. G. B., \& Darido, S. C. (2012). Pedagogia do esporte e das lutas: em busca de aproximações. Revista brasileira de educação fisica e esporte, 26(2), 283-300.

Rufino, L. G. B., \& Darido, S. C. (2013). Possíveis diálogos entre a educação física escolar e o conteúdo das lutas na perspectiva da cultura corporal. Conexões, 11(1), 144-170.

Sacristán, J. G. (2013). Saberes e incertezas sobre o currículo. Penso Editora.

Yazan, B. (2016). Três abordagens do método de estudo de caso em educação: Yin, Merriam e Stake. Revista Meta: Avaliação, 8(22), 149-182. 